\title{
Brief Review
}

$\begin{array}{ll}\text { The new } & \\ & \text { beta-adrenergic } \\ \text { David C. Chung MD FRCP(c), Maria J. Laschuk MD } & \text { antagonists }\end{array}$

For many years propranolol (Inderal) was the only beta-antagonist available in Canada. Since 1977 seven new agents, approved for oral administration only, have become available: metoprolol (Betaloc, Lopressor), nadolol (Corgard), atenolol (Tenormin), oxprenolol (Trasicor), pindolol (Visken), timolol (Blocadren, Timoptic), and Labetalol (Trandate), All are related to propranolol, but have important differences in pharmacologic properties. The relative potencies and recommended doses of these agents are listed in the Table, and a summary of their mode of action, uptake, and elimination follows.

\section{Metoprolol}

Metoprolol differs from propranolol in being a "cardioselective" (beta ${ }_{1}$-selective) antagonist ${ }^{2}-$ that is, it preferentially blocks beta ${ }_{1}$-receptors. (Beta receptors are involved in cardiostimulation and lipo lysis while beta ${ }_{2}$-receptors mediate bronchodilation and peripheral vasodilation.) Theoretically beta ${ }_{1}$ selective agents are superior to non-sclective agents in two important areus: a pure beta, ${ }_{1}$-selective agent should not cause bronchospasm in patients with asthma or chronic obstructive pulmonaty disease and should not cause an increase in peripheral vascular resistance (after-load), as seen with a

\section{Key words}

SYMPATHETIC NER VOUS SYSTEM: sympatholytic agents, beta-adrenergic receptor antagonists.

From the Department of Anaesthesia, Faculty of Medicine, University of Western Ontario, London, Ontario.

Address correspondence to: Dr. D. C. Chung, Dcpt. of Anaesthesia, University of Western Ontario, P.O. Box 5339, Station A, London, Ontario, N6A 5A5. non-selective agent like propranolol. However, it must be stressed that the beta ${ }_{1}$-selectivity of metoprolol is only relative; some degree of beta-receptor blockade is seen in most patients when the daily dose exceeds $100 \mathrm{mg}$.

Metoprolol is recommended for the control of hypertension and angina pectoris. Although absorption from the gastrointestinal tract is almost complete (over 95 per cent of an oral dose is absorbed), there is extensive first-pass hepatic metabolism thus accounting for only a 50 per cent bioavailability. It is broken down in the liver, yielding clinically unimportant and inactive metabolites that are then excreted by the kidneys. The plasma elimination half-life is three to four hours.

\section{Nadolol}

Like propranolol, nadolol is a non-selective betaantagonist; but unlike propranolol, this agent is only weakly lipid-soluble and about 75 per cent of the absorbed dose is excreted unchanged in the urine, with the rest excreted in the bile and other non-renal routes. ${ }^{3}$ It can be removed from the body by haemodialysis. Despite its dependence on the kidneys for elimination, nadolol is not contraindicated in patients with renal failure; but its dose must be adjusted accordingly in these patients and the degree of beta-blockade assessed carefully.

Nadolol is also recommended for the control of hypertension and angina pectoris. Compared with propranolol, nadolol is relatively poorly absorbed from the gastrointestinal tract - only a third of the given dose is absorbed - but first-pass hepatic metabolism does not occur. Its elimination half-life is 14 to 24 hours in patients with nomal renal funetion. Due to this long elimination half-life, nadolol can be given once daily - a dose schedule that has been shown to improve compliance of the patient. 
TABLE Relative potency and dose sehcdule of beta-adrenergic antagonists

\begin{tabular}{|c|c|c|c|}
\hline Drug & Relarive potency ${ }^{1}$ & Maximum daily dose (mg) & Dase schedule \\
\hline Metoprolol* & 1.0 & 400 & bic or tid \\
\hline Nadolo] & 1.0 & $240, \uparrow 320 \neq$ & once daily \\
\hline Atenolol & 1.0 & 100 & once daily \\
\hline Oxprenolol* & $0.5-1.0$ & $480 \ddagger$ & bid or tid \\
\hline Pindolol & 6.0 & $40,+45 \mp$ & $\begin{array}{l}\text { tid when trcating angina or } \\
\text { when dose is over } 30 \mathrm{mg} / \mathrm{day}\end{array}$ \\
\hline Ptopranolol* & 1.0 & 400 & tid or qid \\
\hline Timolol & 60 & $45,+60 \pm$ & bid or tid \\
\hline Labetalcl & 0.3 & 1200 & bid \\
\hline
\end{tabular}

* Slow release preparation available.

†For the control of angina.

¥For the control of hypertension.

'Relative to propranolol.

Since the elimination half-life of nadolol is prolonged as renal dysfunction progresses, ${ }^{4}$ it is recommended that the dose interval should be adjusted to 24 to 36 hours in patients with moderately severe renal impairment (creatinine clearance between 31 to $50 \mathrm{ml} / \mathrm{min} / 1.73 \mathrm{~m}^{2}$ ), 24 to 48 hours in those with severe renal impairment (creatinine clearance between $101030 \mathrm{ml} / \mathrm{min} / 1.73 \mathrm{~m}^{2}$ ), and 40 to 60 hours in those with very severe renal impairment (creatinine clearance $<10 \mathrm{ml} / \mathrm{min} / 1.73 \mathrm{~m}^{2}$ ).

\begin{abstract}
Atenolol
Atenolol, the most recently introduced betaadrenergic antagonist, has properties similar to both metuprolol and nadolol. ${ }^{8}$ Like metoprolol, it is a cardioselective (beta ${ }_{1}$-selective) antagonist; and being only weakly lipid-soluble like nadolol, it is largely eliminated in the urine. This agent is recommended only for the treatment of hypertension. Approximately 50 per cent of an oral dose is absorbed from the gastrointestinal tract, and the maximum dose should not exceed $50 \mathrm{mg}$ daily when creatinine clearance is between 15 and $35 \mathrm{ml} / \mathrm{min} / 1.73 \mathrm{~m}^{2}$ or $50 \mathrm{mg}$ every other day when creatinine clearance is less than $15 \mathrm{ml} / \mathrm{min} / 1.73 \mathrm{~m}^{2}$.
\end{abstract}

\section{Oxprenolol}

Oxprenolol is a non-selective beta-antagonist which exhibits intrinsic sympathomimetic (partial agonist) activities. ${ }^{6}$ That is, while it antagonizes competitively the effects of circulating catecholamines, its interaction with beta-adrenergic receptors causes a weak stimulation of these receptors. As a betaantagonist, an agent with partial agonist activities is as effective as other members of the group in the control of hypertension, myocardial ischaemia and cardiac arrhythmias; but in contrast to agents without intrinsic sympathomimetic activities, it causes less slowing of resting heart rate and less depression of left ventricular function through beta, stimulation, and can decrease peripheral vascular resistance as well as relax bronchial smooth muscle through beta stimulation. Despite these theoretical advantages, however, agents with partial agonist activities should still be used with caution in patients with cardiac dysfunction, atrioventricular conduction abnormalities, peripheral vascular disease and asthma or chronic obstructive lung disease.

In Canada oxprenolol is recommended only for the treatment of hypertension. Oxprenolol is well absorbed from the gastrointestinal tract (70-95 per cent). First-pass hepatic metabolism is variable, and bioavailability after an oral dose is between 24 to 60 per cent. Elimination is largely by conjugation in the liver, yielding a glucuronide metabolite which is then excreted by the kidneys. The elimination half-life is two hours, but the pharmacologic effects last up to twelve hours.

\section{Pindolol}

Pindolol is another non-selective beta-antagonist with intrinsic sympathomimetic activities that are slightly more potent than those of oxprenolol. ${ }^{7}$ It is recommended for the treatment of hypertension and control of angina pectoris. Oral absorption is greater than 90 per cent. Since first-pass hepatic metabolism is near non-existent, bioavailability after an oral dose is also around 90 per cent. 
Approximately 60 per cent of an oral dose is ultimately broken down to inactive metabolites in the liver, and the rest is excreted unchanged by the kidneys. The plasma elimination half-life is three to four hours and is unaffected by moderate renal impairment, indicating that there is an increase in metabolic clearance as renal clearance is reduced.

\section{Timolal}

Timolol is another non-selective beta-antagonist without intrinsic sympathomimetic activities, ${ }^{8}$ In addition to the control of hypertension and angina pectoris, it is approved for topical application as eye drops in the treatment of open-angle glaucoma. Its ability to reduce intraocular pressure may be related to the inhibition of aqueous formation, but this hypothesis remains to be verified.

Orally administered timolol is recommended for the treatment of hypertension and the control of angina. More than 90 per cent of an oral cose is absorbed from the gastrointestinal tract; but bioavailability is only 75 per cent, indicating significant first-pass hepatic metabolism. Approximately 80 per cent of a given dose is transformed to inactive metabolites by the liver and the rest eliminated unchanged by renal clearance. The plasma half-life is three to four hours and is unaffected by moderate degrees of renal dysfunction. Although the ophthalmic dose (onc drop of 0.25 or 0.5 per cent solution into each affected eye, twice a day) is only a fraction of the dose used in the treatment of hypertension and angina, enough is absorbed systemically to precipitate congestive heart failure and bronchospasm in susceptible patients. ${ }^{9}$ Therefore the degree of beta-blockade should be assessed in all ophthalmic surgical patients receiving timolol eye drops. Furthermore, additive systemic effects should bc cxpected when timolol or another beta-antagonist is administered orally or intravenously in patients receiving timolol eye drops.

\section{Labetalol}

Labetalol is unique in having both alpha ${ }_{1}$ and mixed beta receptor blocking activities. ${ }^{11}$ Its betaantagonist action is four times as strong as its alpha-antagonist action, and it is capable of lowering peripheral vascular resistance and blood pressure through alpha blockade as well as preventing reflex tachycardia through beta blockade.

This agent is available now in oral form for the treatment of hypertension; general release of the intravenous preparation is pending. It is well absorbed from the gastrointestinal tract, but undergoes extensive presystemic hepatic metabolism. The bioavailability of oral compared to intravenous labetalol is approximately 25 per cent. The absorbed fraction is mostly conjugated in the liver with glucuronic acid, yielding water soluble metabolites that are rapidly excreted in urine and in faeces. It is of interest to anaesthetists that hepatic and cholestatic jaundice have been reported following treatment with this agent.

\section{Conclusions}

In therapeutics, new drugs do not necessarily have advantages over the parent compounds. This is not true with the new beta-adrenergic antagonists cardio-selective agents are less likely to cause bronchospasm in patients suffering from asthma or chronic obstructive pulmonary disease; agents with partial agonist activities are safer in patients who have ventricular dysfunction, atrioventricular conduction delay, bronchial asthma, and peripheral vascular complications; and poor lipid-solubility together with elimination via the renal route have improved the duration of action. However, protection against these complications is not complete; dependence on renal excretion has made adjustment of the dose in patients with renal dysfunction mandatory; and propranolol is still the only agent available for intravenous administration. These agents are not entirely free of the side-effects attributed to propranolol. Surgical patients treated with the newly introduced beta-adrenergic antagonists deserve the same anaesthetic care as that delineated for patients treated with propranolol ${ }^{10}$ 


\section{References}

1 Frishman WH. The beta-adrenoceptor blocking drugs. Int J Card 1982; 2 165-78.

2 Koch.Weser d. Metoprolol. N Engl J Med 1979; 301: 698-703.

3 Frishman $W_{H}$. Nadolol: A new betd-adrenoceptor antagonist. N Engl J Med 1981; 305: 678-82.

4 Herrera J, Vukovich RA, Griffith $D L$. Elimination of nadolol by patients with renal impairment. $\mathrm{Br} \mathrm{J}$ Clin Pharmacol 1979; 7: 227S-31S

5 Heel RC, Brogden RN, Pakes GE, Speight TM, Avery GS. Nadolol: A review of its pharmacological properties and therapeutic efficacy in hypertension and angina pectoris. Drugs 1980; 20: 1-23.

6 Winchester JF. Drug profile: Trasicor. J Int Med Res 1974; 2: 448-57.

7 Frishman WH. Pindolol: A new beta-adncnoceptor antagonist with partial agonist activity. N Engl J Med 1983; 308: 940-4.

8 Frishman WH. Atenolol and timolol, two new systemic beta-adrenoceptor antagonists. N Engl J Med 1982; 306: 1456-62.

9 Ahmad $S$. Cardiopulmonary effects of timolol eyedrops. Lancet 1979; 2; 1028.

10 Chung $D C$. Anaesthetic problems associated with the treatment of cardiovascular disease: $\mathbf{U}$. Betaadrenergic antagonists. Can Anaesth Soc J 1981; 28: 105-13.

11 MacCarthy EP \& Bloomfield SS. Labetalol a review of its pharmacology, pharmacokinetics, clinical uses and adverse effects. Pharmacotherapy 1983; 3: 193-219. 